\section{Physical activity and health in Brazil: research, surveillance and policies}

\author{
Atividade física e saúde no Brasil: pesquisa, \\ vigilância e políticas
}

\author{
Actividad física y salud en Brasil: investigación, \\ vigilancia y políticas
}

Pedro C. Hallal 1

Thus, a reflection on the Brazilian physical activity and health setting is appropriate. For this purpose, this text is divided in three areas: research, surveillance and policies.

and health became part of Brazilian collectiv health scenario 1 . This phenomenon was similar to what took place elsewhere in the world, although it was a little later, in Brazil. In the 1950s, only $0.01 \%$ of the articles published in Pubmed had the expression "physical activity" in the title or in the abstract. In the 2000s, this proportion increased 50 fold 1 .

A set of articles published in 2012 summarized the knowledge to date of the relation between physical activity and health 2 . Data from 122 countries, representing almost $90 \%$ of the world population showed that $1 / 3$ of the adults are physically inactive, this means, they fall under the recommended 150 minutes per week practice of physical activities 3 . Even more worrisome is knowing that only $20 \%$ of $13-15$ year-old adolescents practice 1 hour a day of moderate to intense physical activities. More than 5 million deaths a year in the world are due to physical inactivity, a figure similar to smoking-related deaths. A set of effective interventions to increase the practice of physical activity among the population is available, but most of these interventions were never expanded on a large scale. The physical inactivity pandemic is considered one of the major global health threats in contemporary societies 2 .

\section{Research}

Research on physical activity and health can be divided, for educational purposes, in five main domains: (a) levels of physical activity and temporal trends; (b) factors associated with the practice of physical activity; (c) consequences of the practice of physical activities; (d) interventions to promote physical activity; (e) policies related to physical activity and health 4 .

The assessment of the local literature makes evident the abundance of studies on the prevalence of physical inactivity and associated factors, but studies on temporal trends are still scarce. Also noteworthy is the lack of studies that use accelerometers in large samples of the population, which can be explained, in part by the tremendous paperwork involved to import equipment to be used in research in Brazil.

In regards to the investigation of factors associated to the practice of physical activity, most studies are still limited to examining the crosssectional association between the practice of physical activity and sociodemographic vari- 
ables. Moreover, studies that associate the practice of physical activity with genetic factors, the study of physical activity in the context of the cycle of life, and detailed investigation of the macro-determinants of behavior are still too scarce and incipient. On the other hand, the influence of the environment on the practice of physical activity has been more and more investigated in Brazil.

In terms of the consequences of the practice of physical activity, most of the data used come from investigations carried out in high-income countries. Some cohort studies on risk factors for chronic diseases, studies on the practice of physical activity by HIV-positive patients, and research on bone health should be highlighted.

As for interventions, Brazil is among the countries with higher quantity and quality of studies available. Differently from the models adopted in high-income countries, in which small interventions are planned within the university walls and tested in a small number of subjects, in Brazil the existing large-scale interventions, with proven sustainability, have been evaluated with the use of innovative combination of methodologies.

\section{Surveillance}

With the establishment and implementation the Risk Factors Surveillance and Chronic Disease Protection by Telephone Inquests (VIGITEL), since the middle of the last decade, Brazil joined the selected group of countries that monitor the annual level of physical activity among the population. The use of an instrument that captures the practice of physical activities in the domains of leisure, commute, work, and housekeeping chores allows the assessment of specific trends of the practice of physical activity in each domain, differently from countries that use instruments that do not separate the activities performed in each one of them. Special heed should be paid to the continuation of the research investigation, as changes made over time make the analysis of temporal trends difficult. The level of physical activities of adults can be also monitored by the National Health Research, which, differently from VIGITEL, uses the home interview approach.

In adolescents, data from Brazilian National School-Based Health Survey (PeNSE, from the Portuguese initials) make possible the assessment of trends, both of the practice of physical activity and the participation in Physical Education classes. In addition, detailed data on exposure to sedentary behaviors, such as TV watching, are available.

\section{Policies}

In the domain of policies, the priority given by the Brazilian Ministry of Health to the area of physical activity and health is unparalleled in the world 5 , having even been highlighted by the journal The Lancet in the series of articles on physical activity published in 2012 2. The National Health Promotion Policy and the Plan to Face Non-Communicable Diseases and Conditions are examples of instrumental documents for the development of this area. However, the mere existence of the documents does not ensure success. A number of countries have detailed plans in the area of physical activity and health, but very little (if anything at all) reached the population.

In Brazil, the governmental encouragement for the promotion of local physical activity interventions was the cornerstone for a number of successful activities in the area. Since the 1990s, a number of large-scale interventions to promote physical activity have been carried out, with the Programa Agita São Paulo ("Stir São Paulo Program") being the best known of these. Local longterm interventions are also carried out in the cities of Recife, Aracaju, Vitória, Curitiba, among others. Since 2005, such actions were leveraged by the government with the allocation of specific funding.

The actions that were developed underwent a series of evaluations, and served as basis for the development of the Programa Academia da Saúde ("Health Gym Program"), with the goal of reaching 4,000 cities by 2014 . In addition, originally, the ordinance that established the Program had the promotion of health activity as its core axis. The challenges posed by reality, however, are a barrier to the program's growth and consolidation. Initially, the construction of the gyms and the commencement of the activities were seriously delayed. Even more worrisome was a change in the ordinance that established the Program, that took the focus away from the promotion of physical activity, and transformed the Health Gym Program (at least in the legislation) into an intervention with no defined focus.

The lack of focus is justified by the use of a broader health promotion perspective, in line with the principles advocated by the Brazilian Unified National Health System (SUS). However, such a perspective cannot be used to denature an intervention clearly focused in a health promotion component such as the practice of physical activities. With no specific focus, the Program runs the risk of being set aside by local governments. Furthermore, the outcomes of all evaluations carried out to date that suggested the ef- 
fectiveness of the program were related to the practice of physical activity.

Still in the domain of policies, it should be mentioned: (a) the existence of a specific scientific society for the field of physical activity and health, that was established prior to the International Society; (b) the existence of a scientific journal specifically for the area of physical activity and health, also created before the international journal of the area; (c) the Brazilian Congress of Physical Activity and Health, originally organized in the 1990s, once again before the international congress in the field. Finally, mention should be made that: (a) in 2014, Brazil hosted the V International Congress on Physical Activity and Public Health. It was the first time the congress took place in a non-high-income country; (b) Brazil had a leadership role in the Lancet's Series on Physical Activity, published in 2012, and leads the Global Physical Activity Observatory.

\section{Conclusions}

The growth of the physical activity and health area in Brazil is evident, whether in research, surveillance or policies. However, for the area to keep on growing, it is essential that researchers no longer duplicate studies carried out elsewhere, particularly enquiries on the prevalence of physical inactivity and associated factors, and venture into more complex investigations. Within the scope of policies, it is fundamental that the Health Gym Program be rapidly expanded in the country, with its essence of promoting physical activity being kept. The challenge for the future is clear: the development of societies in which the decision of being physically active is seen not only as healthy, but also accessible, safe, pleasant, and valued 2 .
1. Hallal PC, Dumith SC, Bastos JP, Reichert FF, Siqueira FV, Azevedo MR. Evolução da pesquisa epidemiológica em atividade física no Brasil: uma revisão sistemática. Rev Saúde Pública 2007; 41: 453-60.

2. The Lancet Physical Activity Series. http://www. thelancet.com/series/physical-activity (accessed on $24 / \mathrm{Jul} / 2014$ ).

3. World Health Organization. Global recommendations on physical activity for health. Geneva: World Health Organization; 2010.

4. Florindo AA, Hallal PC. Epidemiologia da atividade física. São Paulo: Editora Atheneu; 2011.

5. Malta DC, Silva JB. Policies to promote physical activity in Brazil. Lancet 2012; 380:195-6.

Submitted on $24 / \mathrm{Jul} / 2014$

Approved on 18/Aug/2014 